\title{
Possible Pharmacological Approach Targeting Endoplasmic Reticulum Stress to Ameliorate Leptin Resistance in Obesity
}

\author{
Toru Hosoi* and Koichiro Ozawa* \\ Department of Pharmacotherapy, Graduate School of Biomedical and Health Sciences, Hiroshima University, \\ Hiroshima, Japan
}

OPEN ACCESS

Edited by:

Timo Dirk Müller,

Helmholtz Zentrum München,

Germany

Reviewed by:

Paulo Martins,

Royal Canin, USA; Mars Petcare,

USA

Tobias Fromme,

Technische Universität München,

Germany

${ }^{*}$ Correspondence:

Toru Hosol

toruh@hiroshima-u.ac.jp;

Koichiro Ozawa

ozawak@hiroshima-u.ac.jp

Specialty section: This article was submitted to

Cellular Endocrinology,

a section of the journal

Frontiers in Endocrinology

Received: 18 March 2016

Accepted: 25 May 2016

Published: 08 June 2016

Citation:

Hosoi T and Ozawa K (2016) Possible Pharmacological Approach

Targeting Endoplasmic Reticulum

Stress to Ameliorate Leptin

Resistance in Obesity.

Front. Endocrinol. 7:59.

doi: 10.3389/fendo.2016.00059
Obesity is associated with metabolic syndrome, such as diabetes, hypertension, and hyperlipidemia. Therefore, drug development for the treatment of obesity is needed. Leptin is an anti-obesity hormone that inhibits food intake and increases energy metabolism, and, as such, treatments involving leptin were expected to be beneficial for obesity; however, since most obese patients are in a state of leptin resistance, these treatments may not be useful. Therefore, the amelioration of leptin resistance has recently been attracting interest as a treatment for obesity. The mechanisms underlying the development of leptin resistance need to be elucidated in more detail. Endoplasmic reticulum (ER) stress was recently suggested to be involved in the pathogenesis of leptin resistance. The molecular mechanisms responsible for leptin resistance and possible pharmacological treatments for obesity have been discussed herein, with a focus on ER stress.

Keywords: endoplasmic reticulum stress, obesity, leptin, leptin resistance, STAT3

\section{LEPTIN}

Leptin is an anti-obesity hormone that was first discovered by Dr. Friedman's group in the year 1994 (1). It is secreted from adipose tissue and circulates in the bloodstream. Several splicing isoforms of the leptin receptor have been identified to date, such as Ob-Ra, Ob-Rb, Ob-Rc, Ob-Rd, Ob-Re, and $\mathrm{Ob}-\mathrm{Rf}$. Of these, the $\mathrm{Ob}-\mathrm{Rb}$ isoform is the longest and has Box 1,2, and 3 regions, which are important for Janus kinase 2 (JAK2) and signal transducer and activator of transcription 3 (STAT3) binding. Upon binding to the $\mathrm{Ob}-\mathrm{Rb}$ receptor, leptin activates JAK2/STAT3 signaling. The Ob-Rb long isoform is mainly expressed in the hypothalamus $(2,3)$. In addition to the hypothalamus, we also previously demonstrated that a functional leptin receptor of $\mathrm{Ob}-\mathrm{Rb}$ is expressed in the brain stem (4). We reported that leptin has the ability to activate STAT3 signaling in the hypothalamus and the brain stem (4). Since a mutation in the $\mathrm{Ob}-\mathrm{Rb}$ receptor in $\mathrm{db} / \mathrm{db}$ mice results in severe obesity, the $\mathrm{Ob}-\mathrm{Rb}$ receptor is considered to play an important role in the anti-obesity effects of leptin. Furthermore, the importance of Ob-Rb-STAT3 signals from leptin receptors was demonstrated by the replacement of Tyr 1138 in Ob-Rb with a serine residue, which specifically disrupted Ob-Rb-STAT3 signaling in mice, resulting in obesity (5). Other isoforms, such as Ob-Ra, Ob-Rc, Ob-Rd, and Ob-Rf, are the short isoforms of leptin receptors and only have the Box 1 region. These isoforms activate JAK2, but not STAT3 signaling, and, as such, are not involved in the anti-obesity effects of leptin. We previously reported that these short isoforms may play a role in regulating immune function through the induction of interleukin (IL)-1 $\beta$ (6) and IL-1 receptor antagonists (7). However, the physiological roles of the short isoforms of leptin receptors have yet to be investigated in detail. On the other hand, 
the Ob-Re isoform of the leptin receptor is known to be a soluble type that does not have a transmembrane region, and it circulates in the bloodstream and regulates leptin concentrations (8).

\section{LEPTIN RESISTANCE}

The discovery of leptin led to the expectation that leptin therapy may be beneficial for obesity. However, since circulating levels of leptin are elevated with obesity (9), and most obese patients are in a state of leptin resistance, leptin therapy may not be beneficial for most obese patients (10). Therefore, a clearer understanding of the mechanisms underlying the development of leptin resistance is considered as important. One of the mechanisms suggested to be responsible for leptin resistance is the impaired transport of leptin across the blood-brain barrier (BBB) $(11,12)$ (Figure 1). A previous study showed a decrease in the ratio of leptin levels in cerebrospinal fluid versus serum with obesity, suggesting that the capacity for leptin transport is lower in obese patients (13). Furthermore, impairments in leptin-induced STAT3 phosphorylation were demonstrated in a mouse model of diet-induced obesity following a peripheral, but not central injection of leptin (14).

Another possibility for the development of leptin resistance is impaired intracellular signal transduction. Previous studies reported that negative feedback regulators of JAK2/STAT3 signal transduction increase with obesity. Suppressor of cytokine signaling 3 (SOCS3) is a negative feedback regulator (15-18) that acts downstream of the leptin receptor $(19,20)$ (Figure 1). The expression of SOCS3 was previously shown to be regulated through STAT3 and negatively regulates the effects of leptin $(19,20)$. In addition to SOCS3, protein tyrosine phosphatase 1B (PTP1B) also plays a role in inhibiting the effects of leptin by de-phosphorylating JAK2 (21-23) (Figure 1). Furthermore, previous studies demonstrated that SOCS3 and PTP1B levels were elevated in a mouse model of obesity $(19,24,25)$, suggesting the involvement of SOCS3 and PTP1B in leptin resistance with obesity.

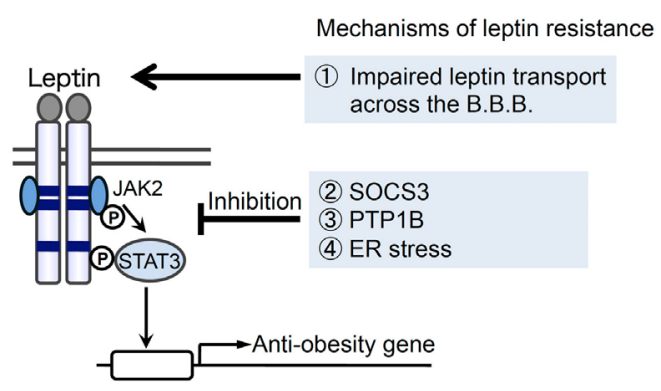

FIGURE 1 | Possible mechanisms for the development of leptin resistance with obesity. Several mechanisms have been suggested for the development of leptin resistance: (1) impaired leptin transport across the blood-brain barrier (BBB), (2) the induction of suppressor of cytokine signaling 3 (SOCS3), (3) the induction/activation of protein tyrosine phosphatase 1B (PTP1B), and (4) endoplasmic reticulum (ER) stress have been suggested to play roles in the development of leptin resistance in obesity.
The endoplasmic reticulum (ER) is an organelle that is involved in promoting protein folding (26-28). Various stresses, which impair ER function, lead to the accumulation of unfolded proteins in the ER and cause ER stress. ER stress has been implicated in several types of diseases, such as neurodegenerative disease, diabetes, and obesity $(18,28)$. Cells activate unfolded protein responses (UPR), such as double-stranded RNA-activated protein kinase (PKR)-like ER kinase (PERK)-eukaryotic initiation factor 2 (eIF2 $\alpha$ ), inositol-requiring enzyme-1 (IRE1)-X-boxbinding protein 1 (XBP1), and activating transcription factor 6 (ATF6) pathways, upon the accumulation of unfolded proteins (26-28). Recent findings suggest that ER stress is also involved in the development of leptin resistance (Figure 1). Previous studies demonstrated that ER stress was enhanced in a mouse model of obesity (29) and was suggested to be involved in the development of leptin resistance (30-32). One of the physiological factors that may cause ER stress is saturated fatty acids. Palmitate, a saturated fatty acid, but not oleate, was shown to increase ER stress in the pancreatic $\beta$ cell line, INS-1 (33). Therefore, the excessive intake of saturated fatty acids may cause ER stress and leptin resistance in obesity. Furthermore, homocysteine has been reported to cause ER stress $(34,35)$. We previously demonstrated that peripherally injected homocysteine induced XBP-1 splicing in the mouse brain (36), and homocysteine inhibited leptin-induced STAT3 phosphorylation in the mouse hypothalamus (30). Since plasma homocysteine levels increase with obesity (37), homocysteineinduced ER stress may also play a role in the development of leptin resistance.

\section{POSSIBLE PHARMACOLOGICAL APPROACH TO AMELIORATE LEPTIN RESISTANCE BY TARGETING ER STRESS}

As discussed above, leptin resistance is associated with obesity, and, thus, its amelioration may represent an important therapeutic approach for obese patients. One of the potential pharmacological approaches for obesity is the use of ER stress modulators. In this review, we focused on the attenuation of ER stress, a recently suggested pharmacological strategy to ameliorate leptin resistance.

Several compounds have been reported to ameliorate ER stress and inhibit obesity. For example, fluvoxamine, a selective serotonin reuptake inhibitor, was previously shown to reduce leptin resistance in neuronal cells (38). Fluvoxamine has affinity for the sigma-1 receptor (Sig-1R) (39), which is an ER protein involved in ER stress (40). Since fluvoxamine has the ability to reduce ER stress through Sig-1R (41), its pharmacological effect of attenuating leptin resistance may be due to a reduction in ER stress (38). In addition to fluvoxamine, another compound attracting interest is celastrol, which was identified in the roots of Tripterygium wilfordii (thunder god vine) (42). It was found to ameliorate hypothalamic ER stress and the development of obesity in mouse models (42).

Chemical chaperones are chemical compounds that assist in protein folding (43) and have been suggested to ameliorate ER stress-induced leptin resistance. For example, the chemical chaperone, 4-phenyl butyric acid (4-PBA), was previously 
reported to ameliorate ER stress-induced leptin resistance (30, 31). Furthermore, the non-steroidal anti-inflammatory drug (NSAID), flurbiprofen, was shown to function as a chemical chaperone and ameliorate ER stress-induced leptin resistance and high fat diet-induced obesity (44). Caffeine also exhibited chaperone activity and reduced ER stress-induced leptin resistance in a neuronal cultured cellular model (45).

In addition to a strategy to ameliorate ER stress through the use of chemical chaperones, pharmacological modulators of UPR may be beneficial. The activation of UPR may induce protein folding signals, which then inhibit the accumulation of unfolded proteins in the ER. The activation of UPR by the overexpression of an ER stress sensor protein has been shown to attenuate ER stressinduced leptin resistance (31). Moreover, the expression of the spliced form of XBP1 in pro-opiomelanocortin (POMC) neurons was found to improve ER stress-induced leptin insensitivity (46). Therefore, future studies to identify and evaluate the anti-obesity effects of these types of compounds, which have the ability to modulate the effects of UPR, will be of interest. On the other

\section{REFERENCES}

1. Zhang Y, Proenca R, Maffei M, Barone M, Leopold L, Friedman JM. Positional cloning of the mouse obese gene and its human homologue. Nature (1994) 372(6505):425-32. doi:10.1038/372425a0

2. Fei H, Okano HJ, Li C, Lee GH, Zhao C, Darnell R, et al. Anatomic localization of alternatively spliced leptin receptors (Ob-R) in mouse brain and other tissues. Proc Natl Acad Sci U S A (1997) 94(13):7001-5. doi:10.1073/ pnas.94.13.7001

3. Mercer JG, Hoggard N, Williams LM, Lawrence CB, Hannah LT, Trayhurn P. Localization of leptin receptor mRNA and the long form splice variant $(\mathrm{Ob}-\mathrm{Rb})$ in mouse hypothalamus and adjacent brain regions by in situ hybridization. FEBS Lett (1996) 387(2-3):113-6. doi:10.1016/0014-5793(96)00473-5

4. Hosoi T, Kawagishi T, Okuma Y, Tanaka J, Nomura Y. Brain stem is a direct target for leptin's action in the central nervous system. Endocrinology (2002) 143(9):3498-504. doi:10.1210/en.2002-220077

5. Bates SH, Stearns WH, Dundon TA, Schubert M, Tso AW, Wang Y, et al. STAT3 signalling is required for leptin regulation of energy balance but not reproduction. Nature (2003) 421(6925):856-9. doi:10.1038/nature01388

6. Hosoi T, Okuma Y, Nomura Y. Leptin regulates interleukin-1beta expression in the brain via the STAT3-independent mechanisms. Brain Res (2002) 949(1-2):139-46. doi:10.1016/S0006-8993(02)02974-8

7. Hosoi T, Okuma Y, Nomura Y. Leptin induces IL-1 receptor antagonist expression in the brain. Biochem Biophys Res Commun (2002) 294(2):215-9. doi:10.1016/S0006-291X(02)00486-2

8. Gorska E, Popko K, Stelmaszczyk-Emmel A, Ciepiela O, Kucharska A, Wasik M. Leptin receptors. Eur JMed Res (2010) 15(Suppl 2):50-4. doi:10.1186/2047-783X-15-S2-50

9. Frederich RC, Hamann A, Anderson S, Löllmann B, Lowell BB, Flier JS. Leptin levels reflect body lipid content in mice: evidence for diet-induced resistance to leptin action. Nat Med (1995) 1(12):1311-4. doi:10.1038/nm1295-1311

10. Friedman JM. A war on obesity, not the obese. Science (2003) 299(5608):856-8. doi:10.1126/science. 1079856

11. Golden PL, Maccagnan TJ, Pardridge WM. Human blood-brain barrier leptin receptor. Binding and endocytosis in isolated human brain microvessels. J Clin Invest (1997) 99(1):14-8. doi:10.1172/JCI119125

12. Banks WA. Leptin transport across the blood-brain barrier: implications for the cause and treatment of obesity. Curr Pharm Des (2001) 7(2):125-33. doi:10.2174/1381612013398310

13. Caro JF, Kolaczynski JW, Nyce MR, Ohannesian JP, Opentanova I, Goldman WH, et al. Decreased cerebrospinal-fluid/serum leptin ratio hand, since the activation of UPR was suggested to be involved in cancer development (47), potential side effects must also be carefully considered when developing drugs to modulate UPR.

Overall, targeting ER stress may be beneficial for the treatment of obesity. This approach may assist in enhancing the effects of endogenous leptin on leptin resistance in obese patients. The identification and elucidation of the pharmacological mechanisms of action of drugs targeting obesity warrant further study.

\section{AUTHOR CONTRIBUTIONS}

TH wrote the manuscript. KO checked the manuscript.

\section{FUNDING}

This study was supported by a Grant-in-Aid for Scientific Research from the Ministry of Education, Science, Sports and Culture, Japan and the Takeda Science Foundation. in obesity: a possible mechanism for leptin resistance. Lancet (1996) 348(9021):159-61. doi:10.1016/S0140-6736(96)03173-X

14. Van Heek M, Compton DS, France CF, Tedesco RP, Fawzi AB, Graziano MP, et al. Diet-induced obese mice develop peripheral, but not central, resistance to leptin. J Clin Invest (1997) 99(3):385-90. doi:10.1172/JCI119171

15. Endo TA, Masuhara M, Yokouchi M, Suzuki R, Sakamoto H, Mitsui K, et al. A new protein containing an $\mathrm{SH} 2$ domain that inhibits JAK kinases. Nature (1997) 387(6636):921-4. doi:10.1038/43213

16. Starr R, Willson TA, Viney EM, Murray LJ, Rayner JR, Jenkins BJ, et al. A family of cytokine-inducible inhibitors of signalling. Nature (1997) 387(6636):917-21. doi:10.1038/43206

17. Naka T, Narazaki M, Hirata M, Matsumoto T, Minamoto S, Aono A, et al. Structure and function of a new STAT-induced STAT inhibitor. Nature (1997) 387(6636):924-9. doi:10.1038/43219

18. Yoshimura A, Ohkubo T, Kiguchi T, Jenkins NA, Gilbert DJ, Copeland NG, et al. A novel cytokine-inducible gene CIS encodes an $\mathrm{SH} 2$-containing protein that binds to tyrosine-phosphorylated interleukin 3 and erythropoietin receptors. EMBO J (1995) 14(12):2816-26.

19. Bjørbaek C, Elmquist JK, Frantz JD, Shoelson SE, Flier JS. Identification of SOCS-3 as a potential mediator of central leptin resistance. Mol Cell (1998) 1(4):619-25. doi:10.1016/S1097-2765(00)80062-3

20. Bjørbaek C, Lavery HJ, Bates SH, Olson RK, Davis SM, Flier JS, et al. SOCS3 mediates feedback inhibition of the leptin receptor via Tyr985. J Biol Chem (2000) 275(51):40649-57. doi:10.1074/jbc.M007577200

21. Zabolotny JM, Bence-Hanulec KK, Stricker-Krongrad A, Haj F, Wang Y, Minokoshi Y, et al. PTP1B regulates leptin signal transduction in vivo. Dev Cell (2002) 2(4):489-95. doi:10.1016/S1534-5807(02)00148-X

22. Cheng A, Uetani N, Simoncic PD, Chaubey VP, Lee-Loy A, McGlade CJ, et al. Attenuation of leptin action and regulation of obesity by protein tyrosine phosphatase 1B. Dev Cell (2002) 2(4):497-503. doi:10.1016/ S1534-5807(02)00149-1

23. Bence KK, Delibegovic M, Xue B, Gorgun CZ, Hotamisligil GS, Neel BG, et al. Neuronal PTP1B regulates body weight, adiposity and leptin action. Nat Med (2006) 12(8):917-24. doi:10.1038/nm1435

24. Morrison CD, White CL, Wang Z, Lee SY, Lawrence DS, Cefalu WT, et al. Increased hypothalamic protein tyrosine phosphatase $1 \mathrm{~B}$ contributes to leptin resistance with age. Endocrinology (2007) 148(1):433-40. doi:10.1210/ en.2006-0672

25. Picardi PK, Calegari VC, Prada PO, Moraes JC, Araújo E, Marcondes MC, et al. Reduction of hypothalamic protein tyrosine phosphatase improves insulin and leptin resistance in diet-induced obese rats. Endocrinology (2008) 149(8):3870-80. doi:10.1210/en.2007-1506 
26. Ron D, Walter P. Signal integration in the endoplasmic reticulum unfolded protein response. Nat Rev Mol Cell Biol (2007) 8(7):519-29. doi:10.1038/nrm2199

27. Walter $\mathrm{P}$, Ron $\mathrm{D}$. The unfolded protein response: from stress pathway to homeostatic regulation. Science (2011) 334(6059):1081-6. doi:10.1126/science.1209038

28. Hosoi T, Ozawa K. Endoplasmic reticulum stress in disease: mechanisms and therapeutic opportunities. Clin Sci (Lond) (2010) 118(1):19-29. doi:10.1042/CS20080680

29. Ozcan U, Cao Q, Yilmaz E, Lee AH, Iwakoshi NN, Ozdelen E, et al. Endoplasmic reticulum stress links obesity, insulin action, and type 2 diabetes. Science (2004) 306(5695):457-61. doi:10.1126/science.1103160

30. Hosoi T, Sasaki M, Miyahara T, Hashimoto C, Matsuo S, Yoshii M, et al. Endoplasmic reticulum stress induces leptin resistance. Mol Pharmacol (2008) 74(6):1610-9. doi:10.1124/mol.108.050070

31. Ozcan L, Ergin AS, Lu A, Chung J, Sarkar S, Nie D, et al. Endoplasmic reticulum stress plays a central role in development of leptin resistance. Cell Metab (2009) 9(1):35-51. doi:10.1016/j.cmet.2008.12.004

32. Schneeberger M, Dietrich MO, Sebastián D, Imbernón M, Castaño C, Garcia A, et al. Mitofusin 2 in POMC neurons connects ER stress with leptin resistance and energy imbalance. Cell (2013) 155(1):172-87. doi:10.1016/j.cell.2013.09.003

33. Karaskov E, Scott C, Zhang L, Teodoro T, Ravazzola M, Volchuk A. Chronic palmitate but not oleate exposure induces endoplasmic reticulum stress, which may contribute to INS-1 pancreatic beta-cell apoptosis. Endocrinology (2006) 147(7):3398-407. doi:10.1210/en.2005-1494

34. Kokame K, Kato H, Miyata T. Homocysteine-respondent genes in vascular endothelial cells identified by differential display analysis. GRP78/BiP and novel genes. J Biol Chem (1996) 271(47):29659-65. doi:10.1074/jbc.271.47.29659

35. Outinen PA, Sood SK, Pfeifer SI, Pamidi S, Podor TJ, Li J, et al. Homocysteineinduced endoplasmic reticulum stress and growth arrest leads to specific changes in gene expression in human vascular endothelial cells. Blood (1999) 94(3):959-67.

36. Hosoi T, Ogawa K, Ozawa K. Homocysteine induces X-box-binding protein 1 splicing in the mice brain. Neurochem Int (2010) 56(2):216-20. doi:10.1016/j. neuint.2009.12.005

37. Narin F, Atabek ME, Karakukcu M, Narin N, Kurtoglu S, Gumus H, et al. The association of plasma homocysteine levels with serum leptin and apolipoprotein B levels in childhood obesity. Ann Saudi Med (2005) 25(3):209-14.

38. Hosoi T, Miyahara T, Kayano T, Yokoyama S, Ozawa K. Fluvoxamine attenuated endoplasmic reticulum stress-induced leptin resistance. Front Endocrinol (2012) 3:12. doi:10.3389/fendo.2012.00012

39. Hanner M, Moebius FF, Flandorfer A, Knaus HG, Striessnig J, Kempner E, et al. Purification, molecular cloning, and expression of the mammalian sigma1-binding site.ProcNatlAcadSciUSA(1996)93(15):8072-7.doi:10.1073/ pnas.93.15.8072

40. Hayashi T, Su TP. Sigma-1 receptor chaperones at the ER-mitochondrion interface regulate $\mathrm{Ca}(2+)$ signaling and cell survival. Cell (2007) 131(3):596610. doi:10.1016/j.cell.2007.08.036

41. Omi T, Tanimukai H, Kanayama D, Sakagami Y, Tagami S, Okochi M, et al. Fluvoxamine alleviates ER stress via induction of Sigma-1 receptor. Cell Death Dis (2014) 5:e1332. doi:10.1038/cddis.2014.301

42. Liu J, Lee J, Salazar Hernandez MA, Mazitschek R, Ozcan U. Treatment of obesity with celastrol. Cell (2015) 161(5):999-1011. doi:10.1016/j. cell.2015.05.011

43. Welch WJ, Brown CR. Influence of molecular and chemical chaperones on protein folding. Cell Stress Chaperones (1996) 1(2):109-15. doi:10.1379/14661268(1996)001<0109:IOMACC>2.3.CO;2

44. Hosoi T, Yamaguchi R, Noji K, Matsuo S, Baba S, Toyoda K, et al. Flurbiprofen ameliorated obesity by attenuating leptin resistance induced by endoplasmic reticulum stress. EMBO Mol Med (2014) 6(3):335-46. doi:10.1002/ emmm.201303227

45. Hosoi T, Toyoda K, Nakatsu K, Ozawa K. Caffeine attenuated ER stress-induced leptin resistance in neurons. Neurosci Lett (2014) 569:23-6. doi:10.1016/j. neulet.2014.03.053

46. Williams KW, Liu T, Kong X, Fukuda M, Deng Y, Berglund ED, et al $\mathrm{Xbp} 1 \mathrm{~s}$ in Pomc neurons connects ER stress with energy balance and glucose homeostasis. Cell Metab (2014) 20(3):471-82. doi:10.1016/j. cmet.2014.06.002

47. Wang $M$, Kaufman RJ. The impact of the endoplasmic reticulum protein-folding environment on cancer development. Nat Rev Cancer (2014) 14(9):581-97. doi:10.1038/nrc3800

Conflict of Interest Statement: The authors declare that the research was conducted in the absence of any commercial or financial relationships that could be construed as a potential conflict of interest.

Copyright (C) 2016 Hosoi and Ozawa. This is an open-access article distributed under the terms of the Creative Commons Attribution License (CC BY). The use, distribution or reproduction in other forums is permitted, provided the original author(s) or licensor are credited and that the original publication in this journal is cited, in accordance with accepted academic practice. No use, distribution or reproduction is permitted which does not comply with these terms. 